\title{
Web and App-based management of flood emergency plans at local entities level
}

\author{
Javier Loizu1,a, Amaya Ruiz² , Ana Varela ${ }^{1}$, Ana Castiella1 ${ }^{1}$ Eva Zaragüeta ${ }^{1}$, Nekane Vizcay², César Pérez ${ }^{2}$, Luis Sanz ${ }^{1}$ and \\ Isabel Macias ${ }^{2}$ \\ ${ }^{1}$ Environmental Management of Navarre (GAN-NIK). C/ Padre Adoain, 219. C.P. 31015. Pamplona-Iruña, Navarre. Spain. \\ ${ }^{2}$ Rural development and environment department, Government of Navarre. C/ Gonzalez Tablas, 9. C.P. 31003. Pamplona-Iruña, Navarre. \\ Spain
}

\begin{abstract}
Different types of floods are frequently causing important economic and personal damages in a variety of locations within Navarre, a region located in northern Spain. Navarre is found very close to the Cantabrian sea, but only about ten percent of its area belongs to that basin, whereas ninety percent of the region belongs to the - Ebro river watershed - Mediterranean basin. Ranging from very humid oceanic climate areas to semi-deserted locations in the south of the region, floods can be caused by persistent winter fronts coming from the Atlantic ocean to very intense convective summer storm events originated in the Iberic mountain range, located to the south of Navarre. The NAdapta Life project includes actions that focus on the mitigation of flood damages. Specifically, the drafting of local emergency plans for small and medium size towns in Navarre is described here. In order to facilitate the flood emergency episodes management, computer tools have been developed for each village selected for the project. Specific websites and smartphone applications have been implemented for each local entity. Awareness, diffusion and training sessions have been carried out along with the implementation of 'drafting and tools' plans.
\end{abstract}

\section{Damages caused by floods in Navarre}

Different types of floods affect Navarre, ranging from flash floods, which occur mainly in central and southern Navarre during summer months, to floods caused by large amounts of softly accumulated rainfall in rainy northern areas of the region. Lastly, some municipalities are also affected by floods caused by the flooding of the main river of northern Spain, which is the Ebro river.

Figure 1 shows the location of Navarre within the Ebro basin. The Ebro river path initiates in northern Spain, not far from the Cantabrian sea, but it flows following a southeastern direction, ending its journey by flowing into the Mediterranean Sea, in southern Catalonia. The Chartered Community of Navarre has a population of 640,000 inhabitants and an area of $10,400 \mathrm{~km}^{2}$.

The climatic conditions within the province vary dramatically, ranging from a very humid and oceanicinfluenced climate in northern areas of the region to areas under extreme Mediterranean climate conditions. While mean annual rainfall in the most north-western areas of the province reaches usually over $2,500 \mathrm{~mm}$, semi-desert locations in the southern part receive recurrently less than $500 \mathrm{~mm}$ per year.

\footnotetext{
${ }^{a}$ Corresponding author: floizuma@gan-nik.es

DOI 10.3311/FLOODRisk2020.17.15
}

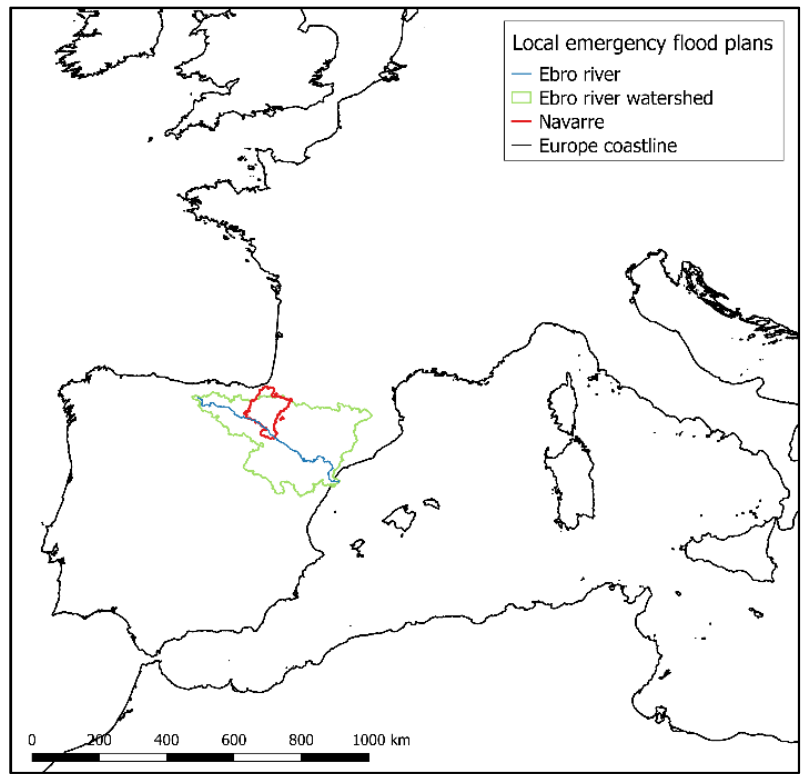

Figure 1. Location of Navarre and boundaries of the Ebro river watershed.

As shown in Figures 1 and 2, $\approx 90 \%$ of Navarre belongs to the Mediterranean basin and the remaining $\approx 10 \%$ to the Cantabrian basin. The main river in the Cantabrian area is 
the Bidasoa river, while main Ebro tributaries are Ega (which flows through the town of Estella-Lizarra), Arga (through Pamplona-Iruña) and the Aragón river, which initiates in the Pyrenees and is highly regulated by Yesa $\left(460 \mathrm{hm}^{3}\right)$ and Itoiz $\left(420 \mathrm{hm}^{3}\right)$ dams.

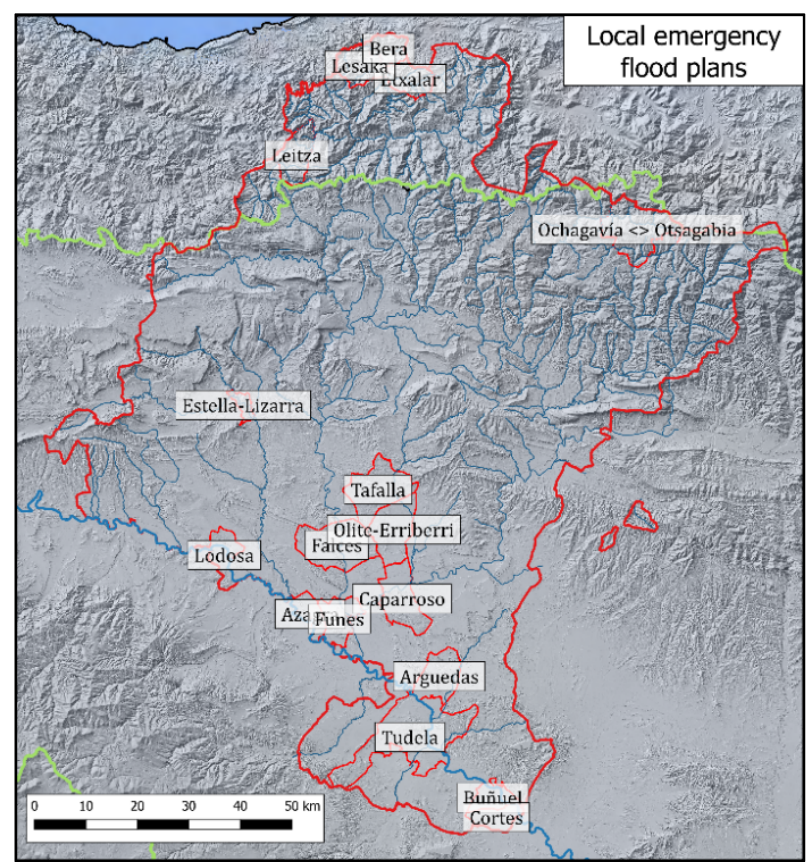

Figure 2. Location in Navarre of the 17 municipalities that will get their local emergency flood plans implemented through the NAdapta Life project.

Figure 2 shows the location of the 17 municipalities (ranging from 1,000 to 35,000 inhabitants) that will get the drafting of their plans financed by the Life NAdapta project (https://lifenadapta.navarra.es/en/). Four of the selected municipalities belong to the Cantabrian basin, while the remaining 13 belong to the Mediterranean Ebro basin. The green line defines the Mediterranean and Cantabrian basin division.

These local entities, attending to the type of flood that they can suffer, can be classified into the following five categories:

1. Humid Atlantic (oceanic) climate influenced area: These include the four municipalities located in the Cantabrian basin. Three of them are located within the main river's catchment that is the Bidasoa river. Municipalities included in that catchment are Bera, Etxalar and Lesaka. While urban areas of Etxalar and Lesaka are not affected by the Bidasoa river itself (tributaries -Tximista and Onin streams - affect those villages), Bera is affected by both the Bidasoa river itself and one tributary (Zia stream).

2. Municipalities in the Pyrenees area, highly influenced by snow accumulation: The village of Ochagavía/Otsagabia is included in this category. Despite Ochagavía and some other villages were already defined as Areas with Potential Significant Flood Risk (APSFR -ARPSI in Spanish-) in the first cycle of the Flood Directive application within the Ebro basin, a larger number of locations was afterwards included in the second cycle of the application of the Directive (6 years period). These additions are due to recent flood events in the area.

3. Towns and villages affected by intermediate size rivers in central Navarre: Estella-Lizarra (crossed by Ega river), Falces and Funes (Arga), Caparroso (Aragón river), Tafalla and Olite/Erriberri, both affected by Cidacos river.

4. Municipalities affected by Ebro River flooding: The flooding of these villages is defined by greater circulation times that allow for an anticipated early warning of several hours, but at the same time, these villages experience higher risks in terms of flowing volumes and larger extensions of the flooding. Furthermore, in most of these villages dykes were constructed in past decades. These dykes have generally resisted previous floods, and have worked efficiently protecting urban areas, but some risky situations have occurred in recent years due to the breaking of some spots of the dykes, causing floods in cultivated areas. Moreover, water expanded into these areas do not easily return to the Ebro riverbed, greatly affecting cultivated fields.

5. Convective storms causing flooding of usually dry gulches that extend into urbanised areas: Gulches characterised by low response-times due to small concentration times. Usually affecting neighbourhoods of one-floor buildings, as it occurs in the village of Caparroso. These are common landscapes in Mediterranean areas, with almost novegetation that could reduce the impact of high intensity storms. Falces, Caparroso or Cortes are some of the villages affected by these type of flash floods, common in southern Navarre.

In the following paragraphs, a description of a selection of the main flood events that have occurred in Navarre in recent years is given. Five events were selected in order to illustrate the type of hazard that floods could cause in different area of the province:

1. Flood in the Bidasoa catchment, specially affecting the municipality of Elizondo (Northern Navarre, Cantabrian basin). Date: $4^{\text {th }}$ of July, 2014.

That day, in the close-by automatic weather station of Gorramendi, over $120 \mathrm{l} / \mathrm{m}^{2}$ were observed within 12 hours. Moreover, the magnitude of this event can be evaluated by the $42 \mathrm{l} / \mathrm{m}^{2}$ observed within one hour that day $(8-9 \mathrm{~h}$ in the morning that day, but could happen during the night anytime). The time of concentration of the Baztan river, in the municipality of Elizondo is about 5 hours, which clearly displays that the time available to local authorities to warn local population is particularly limited. This situation also indicated that emergency-management tools for quick reaction were required in the area. Elizondo was one of the first villages that implemented an App (named Lamia) to manage their flood local plan. This was done thanks to the POCTEFA "H2Ogurea" EFA 062/15 project. 


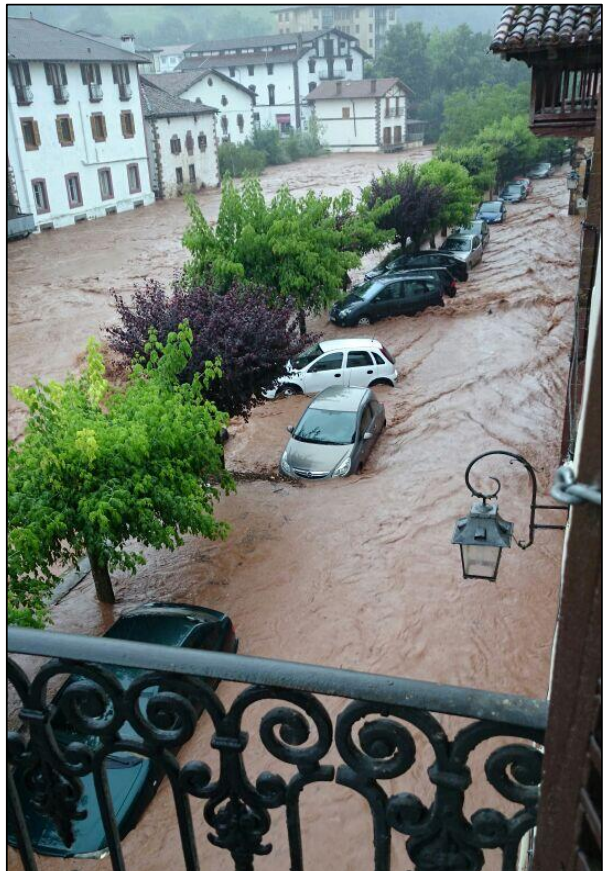

Figure 3. Flood in Elizondo (northern Navarre, Baztan river, Cantabrian basin) in July 2014.

2. Flood in the Anduña and Zatoia catchments that affected, among others in the Pyrenean valleys, the municipality of Ochagavía/Otsagabia. (Pyrenees area, Mediterranean basin). Date: $13^{\text {th }}$ of December, 2019.

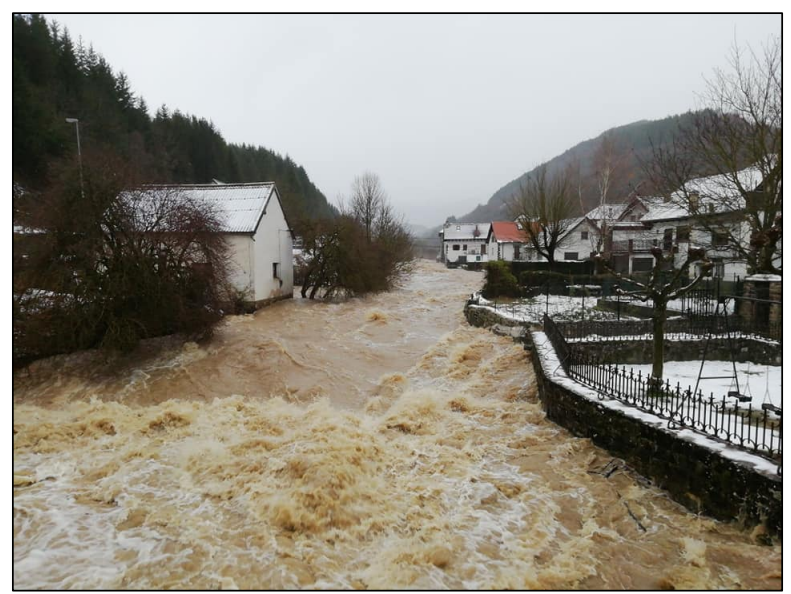

Figure 4. Flood in Ochagavía/Otsagabia (Zatoia and Anduña river confluence, Pyrenean area, Mediterranean basin), occurred in December 2019.

This event caused important impacts in all the valleys that flow in southern direction from the highest mountains of Navarre. Snow had accumulated in the previous days. After that, on the 12 and $13^{\text {th }}$ of December, an important rainfall amount of up to $90 \mathrm{l} / \mathrm{m}^{2}$ (Gorramendi weather station) or $100 \mathrm{l} / \mathrm{m}^{2}$ (Irabia station) within 24 hours was recorded in the area. This came together with an increase of the temperatures, which also contributed to the melting of the accumulated snow. Flooding occurred in several villages including Burgui/Burgi where the three roads that connect to the village where simultaneously flooded.
3. Flood in the Cidacos catchment that affected, among others, the municipalities of Tafalla, Olite/Erriberri and Beire (Central Navarre, Mediterranean basin). Date: $8^{\text {th }}$ of July, 2019.

This was, without any doubt, one of the most hazardous events that occurred in Navarre in recent years. This flooding caused an estimated loss of over 17 million Euro, and one person - a driver - died in his car in one of the ravines affected by the dreadful storm that occurred that day. A series of convective storms initiated in the nearby mountains of La Rioja province (located to the south of Navarre) was the cause for the disaster that took place in the Cidacos catchment. The storms moved following a north-eastern direction, which leaded them into the mountain areas which are the headwaters of the Cidacos river. This includes the catchments of Cemborain $\left(55 \mathrm{~km}^{2}\right)$ or Sansoain $\left(40 \mathrm{~km}^{2}\right)$ streams. Mountains in the upper part of the catchment reach up to $1200 \mathrm{~m}$, while Tafalla and Olite towns are located at $\approx 400 \mathrm{~m}$. altitude. The catchment's area in the gauging station of Olite is $250 \mathrm{~km}^{2}$. That day, the water level increased form $0.1 \mathrm{~m}$. at 16:00 hours to $5.10 \mathrm{~m}$. at $21: 00 \mathrm{~h}$. That meant that the peak reached at least $350 \mathrm{~m}^{3} / \mathrm{s}$, i.e. the highest within the 30 years available records.
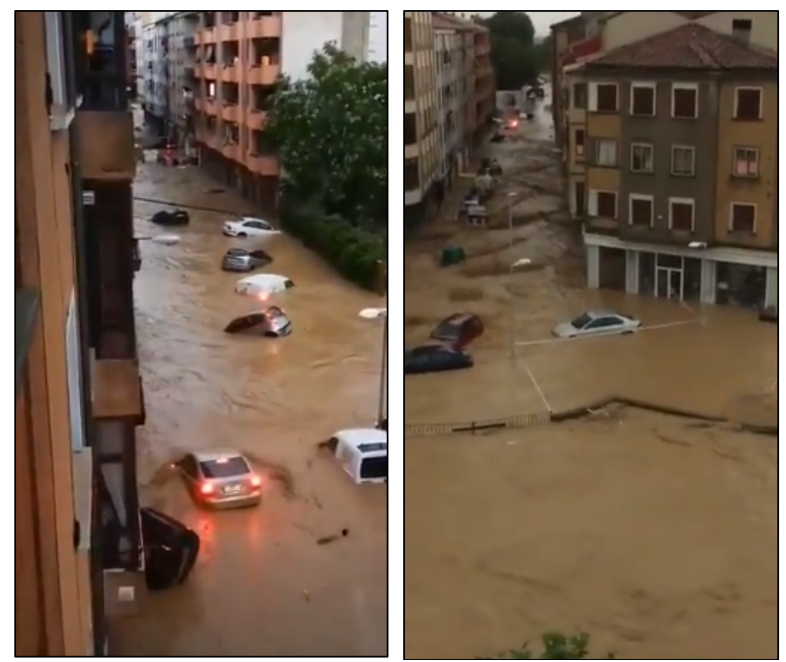

Figure 5. Flood in Tafalla (central Navarre, Cidacos river, Mediterranean basin), occurred in July 2019.

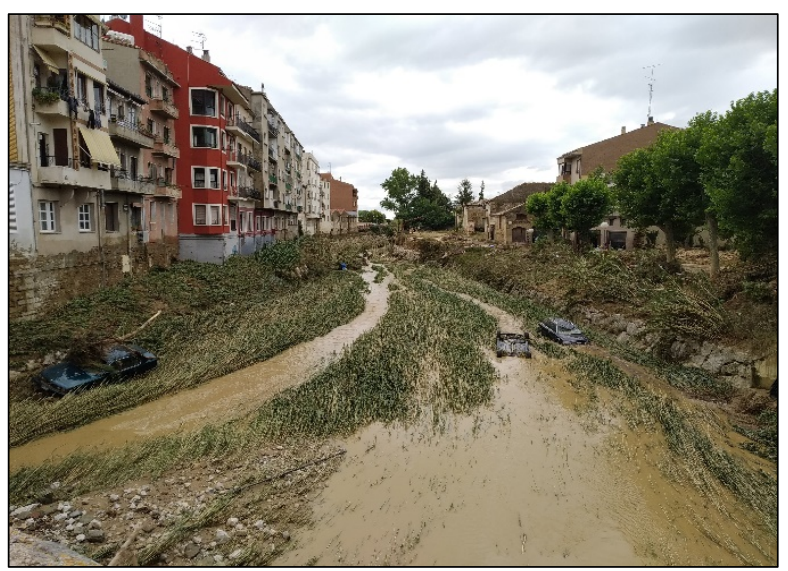

Figure 6. Cars found in the Cidacos riverbed, in the municipality of Tafalla, the day after the flood of the $8^{\text {th }}$ of July (2019). 
Rainfall observed in the area on the $8^{\text {th }}$ of July ranged between the $801 / \mathrm{m}^{2}$ observed in Oloriz (northern part of the catchment) to the $1601 / \mathrm{m}^{2}$ recorded in the highest areas, i.e. weather station at Getadar and the one in Lerga. Stations operating in the municipalities of Tafalla and Olite recorded respectively rainfall rates of 100 and 110 $1 / \mathrm{m}^{2}$ in 24 hours that day. Between 16:00 and 22:00 hours that afternoon - 6 hours period - data observed in the stations of Olite, Tafalla, Barasoain and Getadar were over $90 \mathrm{l} / \mathrm{m}^{2}$. According to the Gumble method, return periods associated to those rates are over 100 years in Tafalla station, between 100 and 500 in Olite and over 500 for the station at the municipality of Lerga (daily data).

Damages were large in the municipalities of Olite, Beire and Pitillas, but the most impressive scenes took place in the municipality of Tafalla, where a large number of cars were completely ruined, due to the high level reached by the river in some of the flooded streets. Furthermore, a significant number of cars were also drowned and moved into the riverbed. They needed to be removed with cranes in the following days after the flooding occurred.

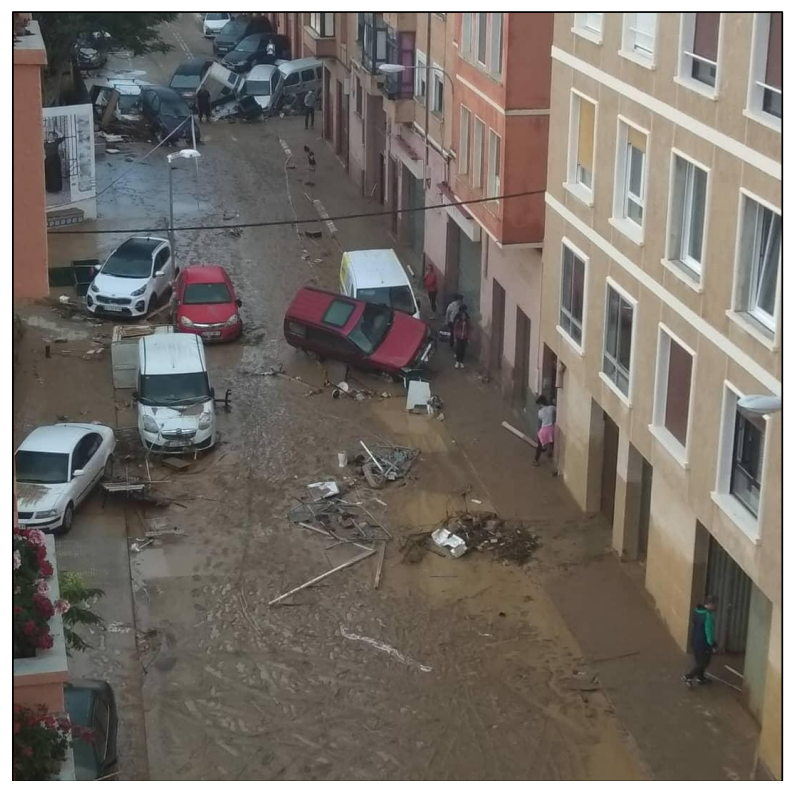

Figure 7. Damages caused by Cidacos river flooding in Tafalla, in July 2019.

4. Flooding caused by the Ebro River, affecting the municipality of Arguedas. (Southern Navarre, Mediterranean basin). Date: $26^{\text {th }}$ of February 2015.

The Ebro River has a total watershed area of $85.000 \mathrm{~km}^{2}$ at its delta in the Mediterranean sea. While it flows throughout Navarre, it accumulates an initial area of $12.000 \mathrm{~km}^{2}$ at the gauging station located in the municipality of Mendavia. That area rises up to 25.000 $\mathrm{km}^{2}$ at the gauging station located in Castejón, once the largest Ebro tributaries that flow through Navarre (Arga and Aragón) are already added to the Ebro streamflow. The accumulated watershed area is of $\approx 27.000 \mathrm{~km}^{2}$ when Ebro river leaves Navarre, and once the Queiles $\left(554 \mathrm{~km}^{2}\right)$ and the Huecha $\left(540 \mathrm{~km}^{2}\right)$ rivers have been also added.

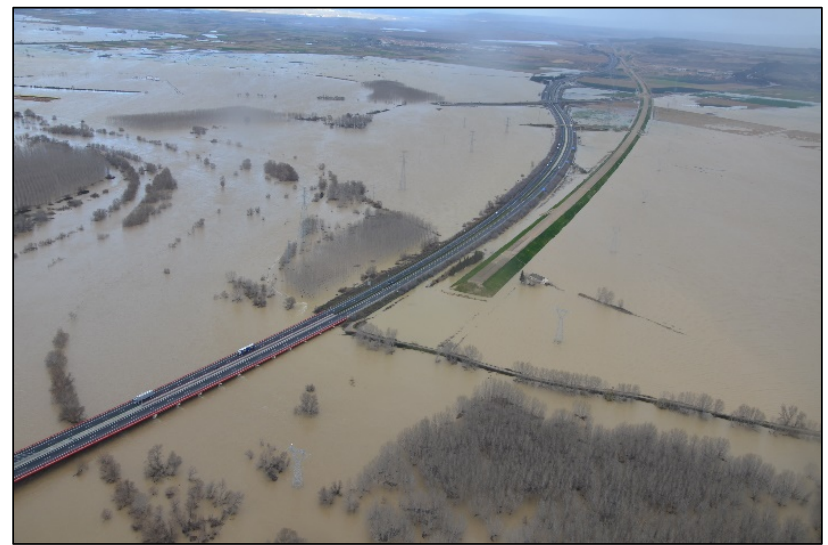

Figure 8. Motorway surrounded by Ebro river flooding in the municipality of Arguedas, in southern Navarre.

Several municipalities have to implement local plans due to the floods caused by the Ebro river itself. Most of them were selected for the NAdapta project, so we are currently working on the drafting of their plans. Selected municipalities include Lodosa, Azagra, Arguedas (Figure 8) Tudela, Buñuel and Cortes. It should be noted that Tudela is the second largest municipality of Navarre. Furthermore, some extra complexity is found on the flood management of some of those towns, including Tudela. Some tributaries flow into the Ebro river in municipalities such as Tudela (Queiles stream) or Cortes (Huecha stream). When the Ebro river increased its streamflow, flooding of the city of Tudela was mainly caused by the entry of water from the Ebro path, into de Queiles path, which flows through the old town of Tudela. In order to avoid that complex and risky behaviour, the Ebro Water Agency recently installed lock-gates at the Queiles mouth.

5. Flood caused by an intense convective storm in the municipality of Cortes (Southern Navarre, Mediterranean basin). Date: $6^{\text {th }}$ of September 2004.

On the $6^{\text {th }}$ of September, an impressive storm took place, affecting large areas of southern Navarre. The network of rainfall recording stations that provide daily data registered that day the extreme value of $175 \mathrm{l} / \mathrm{m}^{2}$ at the near-by stations of Buñuel and Cabanillas. In both cases, the $100 \mathrm{l} / \mathrm{m}^{2}$ rate had been previously exceeded only in few dates. Specifically, since 1929, in the station at Buñuel only 3 dates recorded rainfall rates over $100 \mathrm{l} / \mathrm{m}^{2}$, and the second largest was $120 \mathrm{l} / \mathrm{m}^{2}$. In Cabanillas, the highest value observed before the event of September 2004, was $109 \mathrm{l} / \mathrm{m}^{2}$. These data give a clear impression of the magnitude of the described event, which exceeded all the previous recorded data.

Automatic rainfall observing stations in the area also got impressive values of rainfall during that event. Specifically, the stations in Bardenas (Yugo) and Bardenas (Pol. Tiro) recorded $\approx 1301 / \mathrm{m}^{2}$. Hourly rates in the area were 58, 62 and $61 \mathrm{l} / \mathrm{m}^{2}$ on the three stations located in the Bardenas area, not far from Cortes (Figure 9). 

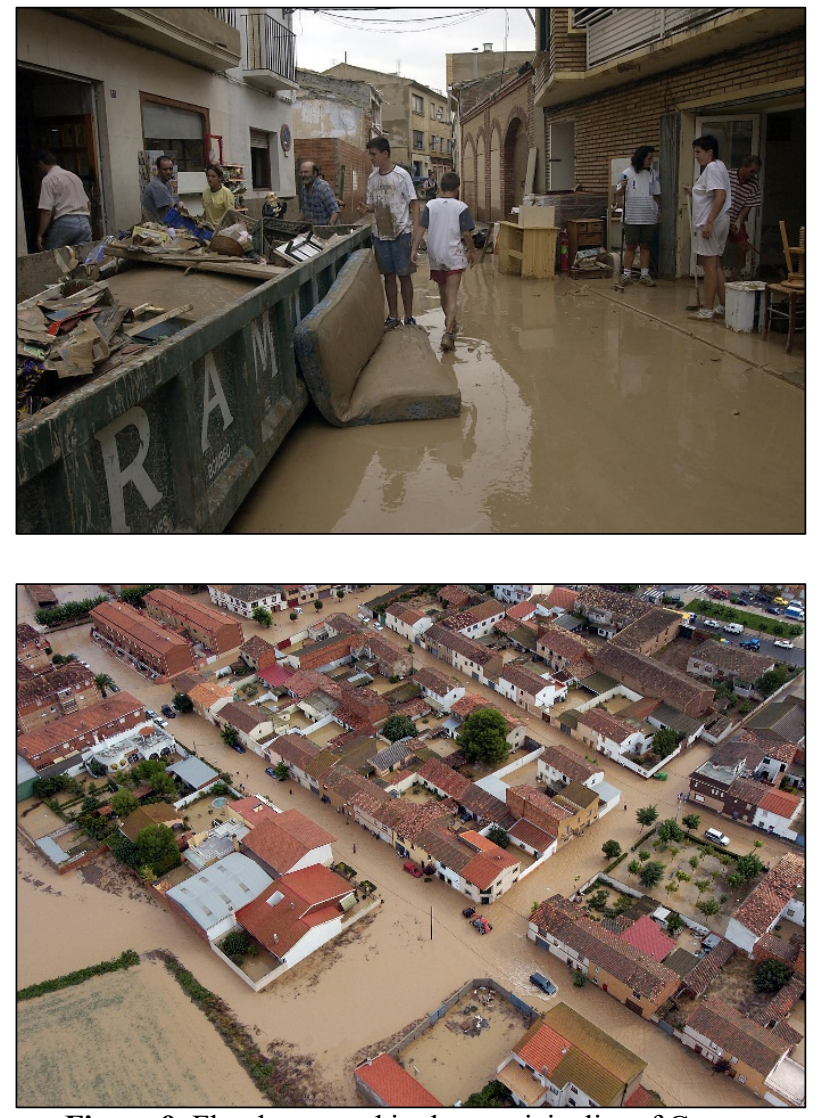

Figure 9. Flood occurred in the municipality of Cortes (Southern Navarre).

The plans for the municipalities of Buñuel and Cortes will be implemented as part of the NAdapta project. The municipality of Buñuel requires the plan only due to the flooding of the Ebro river, whereas Cortes is affected by the confluence of the Ebro and the Huecha rivers. In both cases, the area they are located in is substantially affected by risky convective events, so hydrological and meteorological alerts should be implemented. Similarly, the municipality of Arguedas will also need hydrological and meteorological alerts, as it is affected by the Ebro and by gulches that initiate in the Bardenas semi-desert area. Caparroso and Falces are similar cases, located between Aragon river and "Salado" gulch, and amongst Arga river and "El Pilón" gulch respectively.

\section{The NAdapta Life project}

The NAdapta project was presented to the European Commission for its financial support in April 2017, and the project was finally awarded the European support - and the corresponding agreement was signed - in December 2017. This Life Integrated project was planned with the following main objective: "increase the resilience against Climate Change of the Spanish region of Navarra". The project is focused according to the following areas:

1. Climate Change Monitoring: to define indicators of climate change in Water, Forestry, Agriculture and Human Environment to establish control and alert systems to allow quick and informed decision-making processes.
2. Adaptive Management of Water: managing demand considering variations in availability of water resources resulting specially from climate change and implementing an action plan to facilitate addressing floods and droughts.

3. Forestry: to define new forest growth models in the most vulnerable areas to climate change of Navarra to conserve the ecological value and improve the forest productivity.

4. Agriculture: to implement innovative techniques for adaptation to climate change of soils, use of irrigation water and proper management pasture to ensure agriculture quality and animal health.

5. Health: to define new adaptation measures associated to climate-related diseases (e.g. Asian tiger mosquito or extreme heat waves).

6. Infrastructures and territorial planning: to define adaptive measures of urban environment and housing.

Two main characteristics and strengths of this project should be highlighted. Firstly, that the improvement aimed by this project should follow the principles of: participation, cross-sector, long-term sustainability, subsidiarity, and networking, to share experiences among other regions. Secondly, the geographical diversity of Navarra is a representative region of many habitats, species and diverse economic structure, which will clearly promote the further replication of the project in other European regions.

Specifically, the implementation of flood local emergency plans, and their associated web and App tools, presented in this article, belong to the second area of the project, which are the water-related actions. These plans and computer tools are pilot-experiences that will allow small towns to get the necessary funding for the implementation of up-to-date tools, which otherwise could not afford by themselves.

Consequences of climate change, such as changes in precipitation resulting in flooding and droughts, affect the socio-economic activities and the environment, including the status of water bodies. Climate change scenarios need to be considered to adopt measures to be prepared, prevent and manage the impacts of floods and droughts in urban wastewater facilities and in urban areas. The NAdapta project includes seven water-related actions, which are briefly mentioned here. The fifth action is the one presented here, and it is closely related to the implementation of a Decision Support System (DSS) for flood prevention at a regional scale, including:

- Development of an early warning system facing possible environmental emergencies produced in waste-water treatment plants.

- Development of a monitoring network for Combined Sewer Overflows (CSO) and diagnosis of its environmental impact.

- Adaptation of the urban sewerage networks through the implementation of sustainable drainage systems in urban areas.

- Flood risk warning and automatic alert generating software platform (Action 2.4). 
- Promotion of self-protection plans facing local entities flooding (Action 2.5).

- Drafting of river space recovery projects / preliminary projects as a strategy of conservation and reduction of the flooding impact.

- Evaluation of water resources derived from climate change scenarios and from a demand exploitation model. Demand management plan (supply, irrigation, etc.).

\section{Drafting and dissemination of the plans}

The structure of the local plans is defined on the "Special Plan for Flood Emergency Risk of Navarre", specifically on the last review of the plan, which was performed in January 2018. On this regional plan, it was defined that local plans must contain four different documents, which are the following:

- Document I: Fundaments. Here, plan's objectives are stated. Laws related to water, floods or civil protection are also cited, and previous hydrologic and hydraulic studies available for the area are alluded to.

- Document II: Risk analysis. In this document, a description of the municipality (population, topography, economical activities, and industrial areas) is provided. Moreover, catchments of river and ravines affecting the urban area of the municipality are described. Thirdly, data of previous floods and information on the availability of gauging and meteorological stations in the area are also detailed in this document. Specifically, information of stations observing and sending real-time data is documented. Lastly, a detailed description of the flood specific causes and consequences in the different areas of the municipality is also provided here.

- Document III: Structure and organization._This document is mainly elaborated by the local authorities. The local plans are structured in the following five responsible categories: 1) Plan Director, 2) Head of communication, 3) Municipal Coordination Centre (CECOPAL), formed by between 3 to 5 local authorities and staff. They are in charge of managing the emergency. The fourth position is the responsible to coordinate emergency response with regional authorities, regional civil protection services and water agencies. Finally, the fifth category are the Operative Groups. These groups structure depends largely on the size of the municipality, but in most of the municipalities include local police and the Services Brigade.

- Document IV: Operability and implementation._This last document contains two aspects that are the critical points of the plan: the emergency levels description and the defined hydrological or meteorological thresholds. These local plans have 6 phases to organise the response to an emergency event: preemergency, emergency 0 , emergency 1 , emergency 2 , and emergency 3 . The last level is the deactivation of the plan and is named in the plan as "back to normality" phase. The pre-emergency situation is not to be communicated to general population, but to initiate the streamflow or rainfall rate monitoring by the authorities in charge. Emergency 0 and 1 levels indicate that the expected flood will cause damages only in low areas close to the streambed. On the other side, emergency 2 or 3 warning will indicate population that a flood expected to cause large damages will almost certainly occur in the following hours. The texts that will be communicated to the population to warn them are written in this section of the plan. Proposed texts must send a message to the population, while at the same time avoiding alarm and confusion.

To summarise, the workflow to implement a local flood emergency plan is divided into five different stages, as follows:

1. Initial information review and writing of some of the initial parts of the plan.

2. Second stage is the first presentation and working meeting with the local authorities and staff.

3. Review and writing of the first draft version of the document, through operative information exchange with local technicians (Sometimes, if required, an additional intermediate meeting is performed).

4. Handing over of the plan to local authorities accompanied by the proposal of developing the computer management tool.

5. Dissemination session open to local population (see Figure 10).
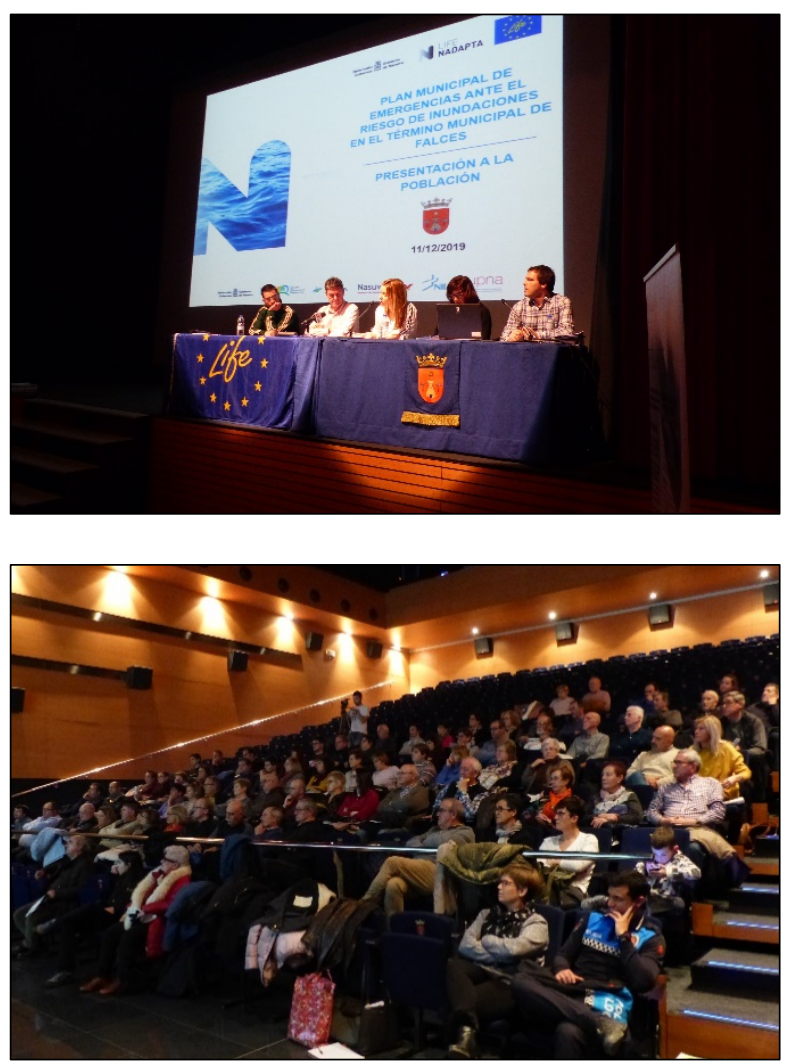

Figure 10. Diffusion session of the plan to local population (Falces, December 2019) 
In the sessions that are open to the general public, an informative brochure was always distributed. In some villages, these brochures were even distributed in each village's house or at least in public buildings before (some days in advance) the session took place. In the public sessions, representatives from the Circular economy and climate change Service of the Government of Navarra, GAN-NIK technicians and the major of each village were always in charge of presenting the local plan and the NAdapta Life project objectives and main characteristics.

\section{Web and App development}

The computer tool for flood emergency management is composed of a Web-based tool and an App programmed for smartphones. Both tools operate synchronised, so when an emergency level is activated in any of the devices, once the website or the App in any other device are refreshed, activated emergency levels will be visible to any other tool user.

The first relevant characteristic of this digitalised mechanism to manage floods at local-level is that the Ebro Water Agency and the Government of Navarre send their streamflow and rainfall data to the local tools in 10 or 15 minutes - real time - basis. As an example, the website where the Government of Navarre shows openly its realtime streamflow data is shown in Figure 11. Those same data are constantly transferred to the Apps that local majors and technicians have installed in their smartphones. Over ten years ago, the Ebro Water Agency and the Government of Navarre reached an agreement in order to exchange mutually the streamflow data observed by each organization's devices installed in different rivers of Navarre. The Government of Navarre shows those data in the following website: http://www.navarra.es/appsext/AguaEnNavarra/ctaMapa. aspx?IDOrigenDatos=1\&IDMapa=1, while the Ebro Water Agency makes its data available through its SAIH network, accessible through the following link: http://www.saihebro.com/saihebro/index.php?url=/datos/ mapas/tipoestacion:A. The Cantabrian Water Agency also has its own streamflow observing network, but at the time of writing this paper, no plan has been finalised in the cantabrian area, and access to the Cantabrian Water Agency data has not been yet requested.

So far, streamflow data have been obtained from Ebro Water Agency servers and from GN servers. While most plans will simply be implemented based on observed streamflow, some other plans will need alerts to be defined based on accumulated-rainfall rates.

Regarding rainfall observation, four different stationnetworks are available within Navarre: Ebro and Cantabrian water agencies', the network maintained by the $\mathrm{GN}$, and finally the one that belongs to the Spanish Meteorological Agency (AEMET). The one of the GN is managed by "Meteonavarra" organization, which is a public unit of the GN that manages meteorological data.

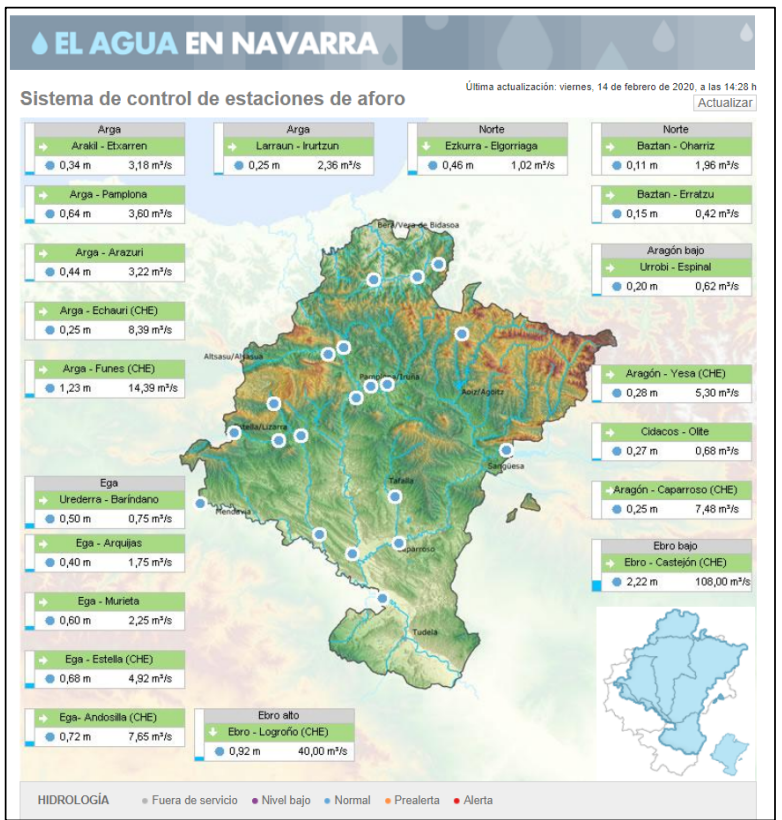

Figure 11. Government of Navarre's website displaying real time streamflow observed data.

Rainfall data observed by the GN's network are available at:

http://meteo.navarra.es/estaciones/mapasdatostiemporeal. $\underline{\mathrm{cfm}}$, and data observed by the Ebro Water Agency network can be accessed through the following link:

http://www.saihebro.com/saihebro/index.php?url=/datos/ mapas/tipoestacion:P.

Lastly, data from the Spanish Meteorological Agency (AEMET) station network will also be used to establish alerts for the local plans. Real-time meteorological data observed by AEMET stations can be accessed through its website, which is organised by province:

http://www.aemet.es/es/eltiempo/observacion/ultimosdat os? $\mathrm{k}=$ nav\&w $=0$. As an example, in figure 12 it is shown the rainfall recording station (owned by Ebro Water Agency, CHE) used for the plan of the municipality of Falces, since it is affected by gulch flooding.

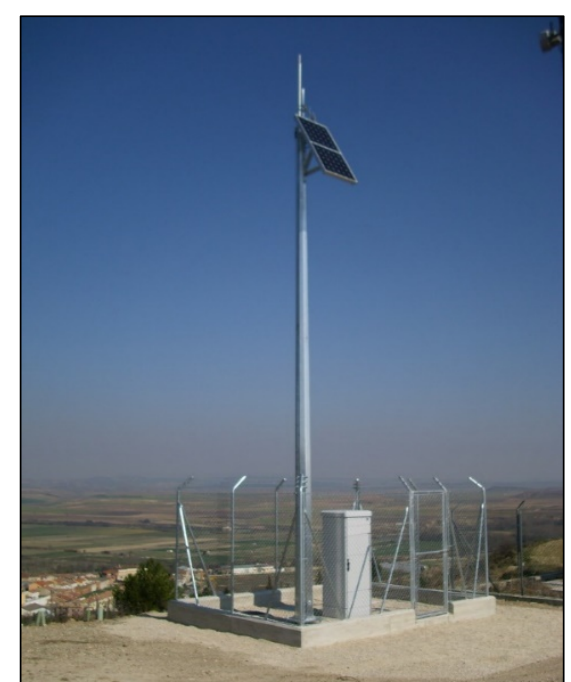

Figure 12. Meteorological station installed in the municipality of Miranda de Arga (Ebro Water Agency) 
In the drafting of the plans process, emergency levels are stablished sometimes in terms of added streamflow flowing in the different rivers towards the municipality to be protected (hydrological thresholds), while some other times, accumulated rainfall rates are defined as thresholds to activate flood alerts (meteorological thresholds).

Characteristic thresholds established in the plans implemented so far are the following: In Estella-Lizarra, the stream flows observed in the Urederra and Ega rivers are added in real time-bases, providing an hydrologicallybased alert that allows local authorities to receive an early warning about 7 hours prior to town's flooding. In this case, no meteorological alert was required. Differently, in Caparroso, both hydrological and meteorological thresholds were stablished. The hydrological one (addition of 4 rivers' streamflow) was proposed due to Aragón river flooding, and an anticipation of 10-11 hours is gained for flood prevention. In this village, a risky gulch made also necessary the establishment of a meteorological alert. In this case, a rainfall observing station, owned by the CHE was available in the village centre itself, and was thus used to observe adverse stormy events. Convective events could very severely affect a large neighbourhood of Caparroso, made of one-floor houses. Similarly, in the municipality of Falces both hydrological and meteorological alerts needed to be implemented. Otherwise, for Funes two sets of hydrological thresholds were required, as the urban area of this village could be affected by both Arga and Aragon river flooding.

In both Caparroso and Falces, rainfall alerts were established based on the analysis of previous flooding episodes occurred in local gulches, and thresholds for 0.5 , 1 and 3 hours accumulated values were defined.

\subsection{Web-based tool specificities}

At the time of writing this paper, four websites were already available. Those are the following, implemented for the municipalities of Estella-Lizarra, Caparroso, Falces and Funes.

- https://www.bola-estella.tesicnor.com/

- https://www.avenida-caparroso.tesicnor.com/

- https://www.riada-falces.tesicnor.com/

- https://www.riada-funes.tesicnor.com/

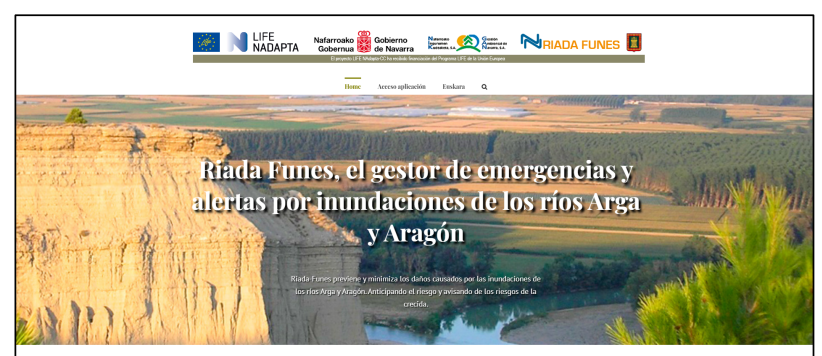

Figure 13. Home page of the website created to provide information on the local plan of Funes.

These websites have three main functionalities:

1. Provide local population with information about the plan. This includes that the full document, the defined thresholds and the maps prepared for the plan are available for download in the "Documentation" tab.
2. Allow subscription for receiving SMS's. In this tab, local-entity inhabitants or interested visitors can provide their mobile telephone number and register for the warning system. Once registered, the interested person will receive the text messages informing on the activation of different emergency levels, sent by local authorities.

3. Access to the emergency management tool section. One of the App's tabs gives (only to local authorities and plan directors) access to the management computer tool.

It is important to highlight that every time that hydrometeological sensors (gauging stations or rainfall observing stations) exceed an established threshold, local authorities and municipal staff involved will receive an email and a warning on their mobiles.

Figure 14 shows the appearance of the web-based management tool, which is only accessible to emergency plan managers. The main characteristics of the tool can be clearly identified. First, in the upper part the "tools bar" options are found. From there, several options can be reached: 1) File, where users' data are stored, 2) Support, where the manual of the tool is found (PDF document to be downloaded), 3) Administration management (plan directors or standard users' rights are defined here) and 4) Emergency Management options. This last link gives access to: management centre, historic management data, drill option and configuration options.

The second main panel is the one located in the left part of the screen, where real-time observed data are shown. Streamflow data for hydrologically-based plans or rainfall data can be observed in this part. Finally, on the right part of the screen a GIS-map viewer has been implemented. Boundaries of the controlled watersheds are shown in this screen.

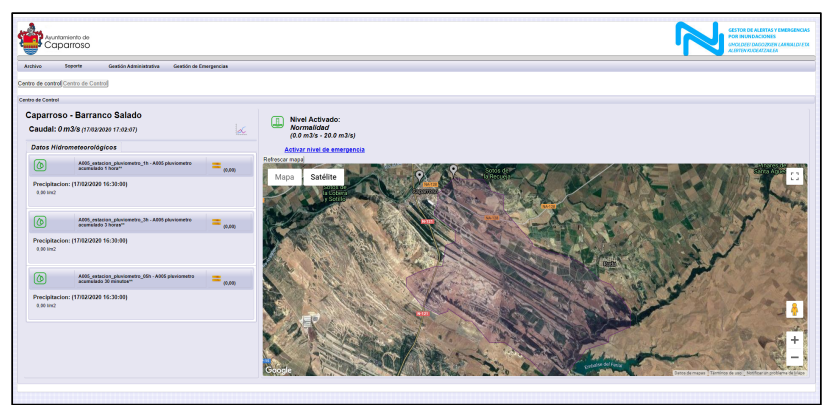

Figure 14. Web-based local plans' management principal screen. Specifically the "Salado" gulch area in Caparroso.

Once the first emergency level (usually emergency 0) is activated, the tool will immediately change its appearance. As can be seen Figure 15, the expected flood extent in the municipality will be shown, represented by a semi-transparent blue layer. Furthermore, red points will indicate the exact coordinates of the locations where Operative Groups need to carry out their respectively assigned actions (i.e. streets closing, cars removal, inhabitants' door-to-door warning, etc.). 


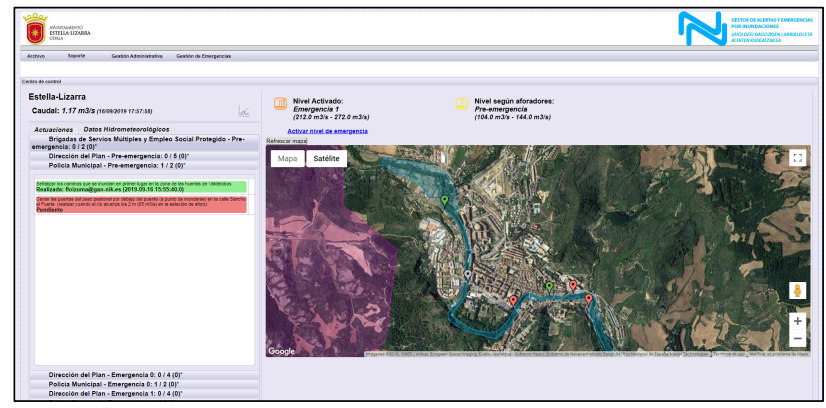

Figure 15. Emergency level 1 situation activated in EstellaLizarra.

Once each responsible (local police, services brigade, etc.) carries out each action, they will (usually through their App) mark the action as "Done" which will mean that the signalled point will change its colour to green, and all the remaining managers and staff involved in the operative will be notified that the action has been done.

Historic data on the time at which each action was done will be kept in the Historic data tab of the website. Moreover, actions can be marked as "in progress" and they will appear in orange colour in the web and in the Apps. A coloured list of the actions "done" and "to be done" also appear in the left part of the web.

Lastly, in the upper part of the screen, the activated emergency level is shown (i.e. emergency 1 in figure 15), and the level recommended by the gauging stations or the rainfall observing stations is also shown (in figure 15, stations suggested pre-emergency situation, but this was just an example for illustrative purposes but not a real scenario).

\subsection{App specificities}

In Android devices the App can be downloaded from the Play Store:

https://play.google.com/store/apps/details?id=com.tesicn or.lamia, and through the Apple Store for IOS devices.

The App is to be used only by plan managers (local authorities and staff), not by general population.
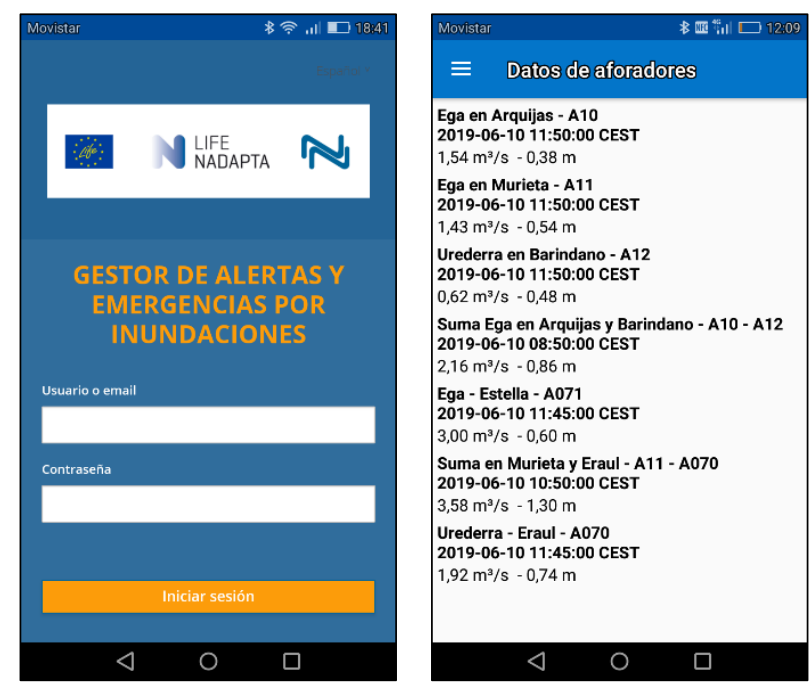

Figure 16. Screenshot of App's initial screen (left). Tab showing gauging or rainfall observing stations data, received in real-time (right).
First, in order to access to the App, the users name and password need to be provided to the App. Only users that had previously obtained access permissions can now access to the app. The company that implemented the computer tool is in charge of creating new users' profiles to validated users from the local entities, the Government of Navarre and GAN-NIK company. Government of Navarre responsible managers and GAN-NIK technicians have access to all the developed Apps.

The App has the following pages that can be accessed from the menu tab:

- Initial screen (Figure 16, left image). User name and password need to be provided here to access the plan's associated App.

- Summary. Here, if any threshold is exceeded, a warning will appear. There are also shown here the activated emergency level, and the emergency level recommended by the hydrometeological sensors.

- Emergency levels (Figure 17, left image). Through the buttons implemented in this screen, plan directors can activate the successive emergency levels (this action can also be done through the web-version of the tool).

- Availabilities (Figure 17, right image). Once an emergency plan is activated, initiated usually from emergency 0 level, involved local entities politicians and staff will have to let other agents involved know their availability. By clicking the corresponding button, their availability state will change from red to green colour.
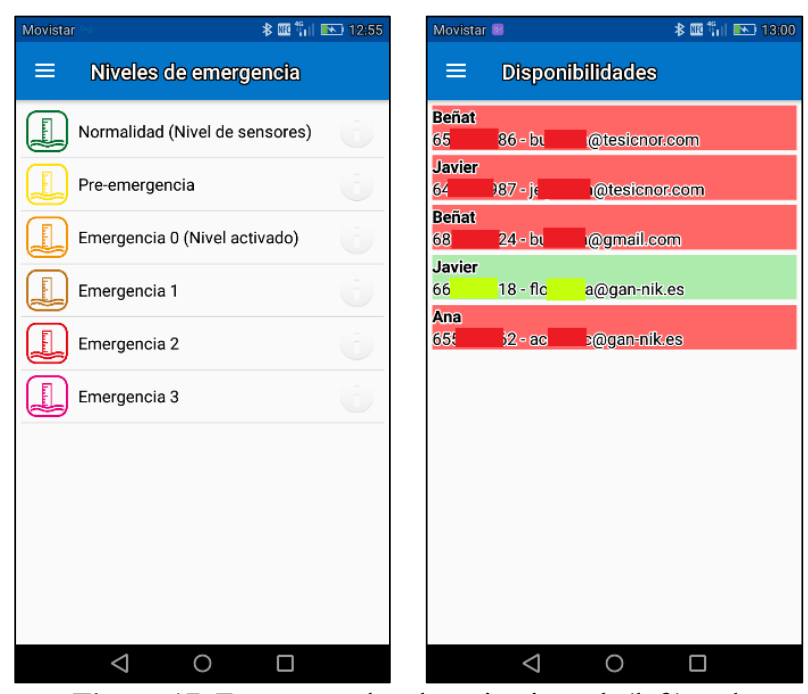

Figure 17. Emergency levels activation tab (left) and availability tab (right).

- Action cards. For each operative group and emergency level, a series of actions were defined during the drafting of the plan. Each operative group member can only see the actions that they got assigned. On the contrary, plan directors can visualize all the actions assigned to the different operative groups, and whether those actions have been done or not, at every moment.

- Gauging and rainfall observing stations real time data (Figure 16, right image). In this tab, all the hydrometeological data used to stablish flood risk 
alarm thresholds are shown, in real time. These data are directly received from water agencies, meteorological agencies or the GN computer servers. The shown values will turn into red colour every time a threshold is exceeded.

- Close session. This button is used to leave the App. In must be noted that closing the App will end receiving the alert notifications. So leaving the App logged in is decidedly recommended.

\section{Local authorities and technicians training}

In each of the local entities, a training session was carried out in order to secure the correct management knowledge of the tool by local authorities and technicians. These sessions were leaded by technicians of the company that developed the tool (Tesicnor S.L.), who were accompanied by technicians from the public company GAN-NIK, in charge of the drafting of the plans. In some cases, due to changes of the local authorities following an election process that took place in May 2019, the plan was further explained to the newly elected majors.
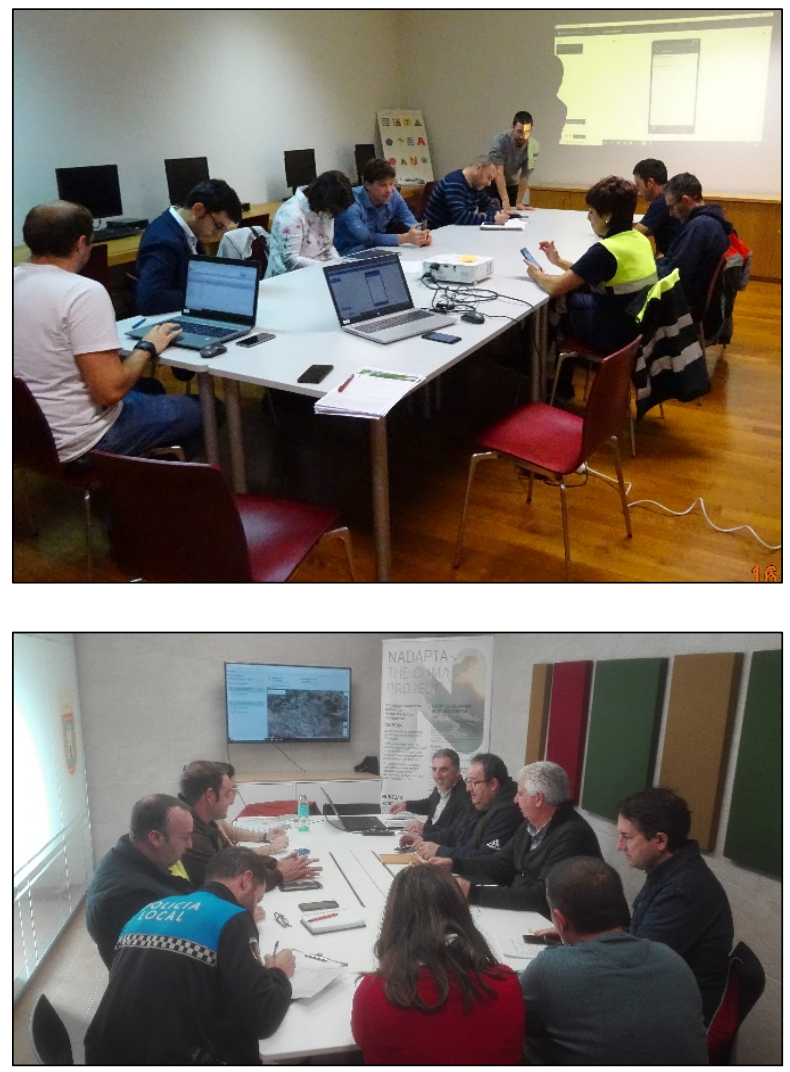

Figure 18. Training sessions with local authorities and staff in the municipalities of Estella-Lizarra (upper photograph) and Funes (lower photograph).

Usually three categories - officially named Operative Groups in the local plans - are involved in the management of a local flood emergency plan. These are the following:

1. Majors (and town councillors and deputy mayors).

2. Local police.

3. Services brigade.
As described before, each operative group gets its specific actions assigned during the plan implementation process. The App and the Web allow then a constantly synchronised operational mode, where local authorities ("Plan Directors") can supervise the adequate realization of each of the actions specified in the local emergency plans.

Majors or deputy mayors are usually assigned the responsibility of formally activating the plan, and they are also responsible of the activation of the successive emergency levels. In municipalities where no head of communications, different from the major has been designated, majors also have the great responsibility of sending the SMS text communications to the population Local police (if available in the municipality) is usually in charge of managing the diversion of the traffic within the municipality in case streets and roads get flooded. Furthermore, they could be in charge of warning population through loudspeakers installed in their cars or of the door-to-door warning. Lastly, services brigades are usually in charge of signposting flooded areas and constructing temporary walls or small dykes if required. Brigade is also usually responsible of repairing affected local infrastructures.

\section{Summary of progress achieved so far and synergies with other actions of the project}

At the time of writing this paper (February 2020), 4 of the 17 municipalities included in the NAdapta project had already received the final versions of their local plans, and their websites and Apps are fully operational. These are Estella-Lizarra, Falces, Funes and Caparroso. Furthermore, in the municipalities of Tafalla, Olite/Erriberri, Lesaka, Etxalar, Lodosa and Azagra initial meetings in each town hall have been already carried out.

All the work carried out in collaboration with the municipalities' politicians and technicians, and the diffusion to the local population performed will clearly improve the flood risk awareness on regional basis in Navarre.

All this wide process will also contribute to an enhanced capacity building, to achieve better measures for reducing flood economic and personal damages, at local entities level. These web-based and Apps are very useful tools for current climatic conditions and for the expected higher flood recurrence rates due to the impact of the different climate change scenarios.

The action 2.5, of NAdapta project, as mentioned before in section 2 (project description) is in a general manner named "Promotion of self-protection plans facing local entities flooding". This action consists of five activities, which are the following: Activity 1 was the prioritization of the municipalities to be selected (the mentioned 17 were selected). Activity 2 is the drafting of the plans. In addition, activity 3 is the implementation and programming of the websites and Apps. The last one, activity 5 , is the conduction of a participation process with local authorities, staff and population, which is carried out simultaneously along with all the other activities. 
The remaining one is Activity 4, which we consider that it should be highlighted here. That activity is the acquisition and installation of new hydro-meteorological sensors in the catchments of those municipalities without previous existing observing devices.

We think that this fourth activity, currently in progress, complements very adequately the remaining actions, as it will financially support the installation of new sensors that will be used to define the streamflow or rainfall rates, that once exceeded, will activate the different emergency levels of different municipalities.

Locations for new rainfall observing stations in different municipalities including Lesaka, Etxalar and Ochagavía/Otsagabia are currently been evaluated. Furthermore, adequate locations for streamflow observing devices installation in the Bidasoa and Elorz rivers are also being studied. These new gauging stations would be highly useful for the implementation of the local plans in Bera and Galar local entities. It is expected that the installation of about six stream gauging stations and/or rainfall recording stations will be financed.

Finally, it has to be mentioned that this action (2.5) is very closely related and have to be implemented in a fully coordinated way with the tool developed in the 2.4 action. Action 2.4 is the implementation of a "Flood risk warning and automatic alert generating software platform". This tool, also named as "Decision Support System" will combine ground and radar based rainfall observations, and will thus provide meteorological flood alerts, specifically focused on flash floods prevention and early warning. In larger catchments, hydrological simulations and streamflow observation will be also included within the tool. Both local plans thresholds and those stablished in the regional platform need thus to be synchronised and coordinated.

\section{Conclusions}

Some significant achievements and strengths of these local plans and their associated computer management tools can be summarised as follows:

- The Life NAdapta project allows financial support for the development of up-to-date flood risk protection tools in small towns which otherwise could not afford by themselves.

- The successful development of these tools rely largely on the dense and well maintained hydrological and meteorological networks available in the region that provide a significant number of real-time observations.

- Local plans provide a defined and well-structured response guide that will help avoiding chaos situations and will lead the actions to be done by each operative group and at each emergency level.

- Early population warning trough the implemented system (i.e. massive text messages submission) will effectively reduce personal and economic damages.

- The development and diffusion of these local municipality level - plans greatly contributes to the increase of flood-related awareness and capacity building at the regional scale.

\section{References}

1. Websites of the developed local entities flood emergency plans:

- https://www.bola-estella.tesicnor.com/

- https://www.avenida-caparroso.tesicnor.com/

- https://www.riada-falces.tesicnor.com/

- https://www.riada-funes.tesicnor.com/

2. Website of the NAdapta Life project:

- https://ifenadapta.navarra.es/en/ 